\title{
Dante en la música española: la Divina Comedia de Conrado del Campo, del poema sinfónico a la ópera
}

\author{
Víctor Sánchez Sánchez \\ Universidad Complutense de Madrid \\ victorsanchez@ghis.ucm.es
}

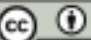

\section{Resumen}

El tema del Infierno de la Divina Comedia ha inspirado numerosas composiciones musicales, tanto en el campo sinfónico como en el operístico. Entre los temas el más utilizado ha sido la trágica historia del amor de Paolo y Francesca. Las versiones operísticas ofrecen diferentes variantes estilísticas desde la tradición italiana de Mercadante, Cagnoni o Zandonai hasta el wagnerismo romántico de Rachmaninof o Mancinelli, pasando por la trivialización de Thomas. En el caso español resulta del mayor interés las composiciones de Conrado del Campo, un compositor muy influido por el romanticismo centroeuropeo, que se acerca al mundo de Dante tanto en la música sinfónica (La Divina Comedia I9Io) como en la ópera (La tragedia del beso I9I5). En estos proyectos resultó decisivo el encuentro con el poeta Carlos Fernández Shaw.

Palabras clave: Francesca da Rimini, Poema sinfónico, Ópera española, Libreto, Carlos Fernández Shaw, María Guerrero, Conrado del Campo.

\begin{abstract}
Dante's Inferno has inspired many musical compositions, both symphonic and operatic field. Among the topics the most used has been the tragic love story of Paolo and Francesca. Operatic versions offer different styles from the Italian tradition of Mercadante, Cagnoni or Zandonai to the romantic Wagnerian of Rachmaninoff or Mancinelli, through the French trivialization of Thomas. In the Spanish music compositions by Conrado del Campo, a composer influenced by the Central European Romanticism, approaches the Dante's world in symphonic music (La Divina Comedia I9I0) and opera (La tragedia del beso 1915). In these works was decisive the encounter with the poet Carlos Fernández Shaw.
\end{abstract}

Keywords: Francesca da Rimini, Symphonic Poem, Spanish Opera, Libretto, Carlos Fernández Shaw, María Guerrero, Conrado del Campo. 
T a Divina Comedia se revalorizó en la cultura europea del XIX en sintonía L con el Romanticismo musical. En el mundo sinfónico los dos ejemplos más conocidos son la Sinfonía Dante de Franz Liszt (I857) y el poema sinfónico Francesca da Rimini de Chaikovski (1876). En el primer caso, Liszt realiza una de sus obras más ambiciosas intentando expandir el modelo de poema sinfónico para representar los tres ejes del viaje (infierno, purgatorio y paraíso). Wagner le aconsejó que no intentase describir el paraíso, así que concluyó con un Magnificat para coro, una especie de visión lejana de lo celestial. Liszt anota en su extensa partitura sinfónica citas de Dante que nos dan las claves programáticas del discurso musical. El momento central del infierno es un Andante amoroso donde copia los famosos versos del canto V ("Nessun maggior dolore / che ricordarsi del tempo felice / nella miseria") en referencia a la trágica historia de Paolo y Francesca. En el caso de Chaikovski, subtitulada Fantasia sinfónica a partir de Dante, se centra directamente en el mismo episodio copiando los versos de Dante al inicio de la partitura. Compuesta bajo una fuerte influencia wagneriana (tras asistir en Bayreuth al estreno de $E l$ anillo del nibelungo) sigue el modelo de Liszt como forma libre de inspiración literaria; de hecho el propio Liszt había subtitulado su Sonata para piano Après une Lecture du Dante: Fantasia quasi Sonata. En ambos casos el contraste entre el amor y la muerte ofrece un intensísimo marco musical lleno de efectos sonoros, sobre una forma ternaria, donde la historia de amor constituye el lírico movimiento central.

Las resonancias del tema de Dante en la música española se dejaron esperar. No será hasta comienzos del siglo XX cuando los músicos se inspiren en la Comedia. Enrique Granados compone su poema sinfónico Dante partiendo de los dos momentos más musicales: el inicio (el encuentro de Dante y Virgilio) y la trágica historia de Paolo y Francesca. Casualmente los mismos dos episodios en que por esas mismas fechas trabajaba orquestalmente el madrileño Conrado del Campo. La presencia de sonoridades wagnerianas, inspiradas en el mundo de Tristán, supone un estímulo fundamental. Si en el caso de Granados el proyecto a modo de sinfonía en cuatro movimientos quedó inacabado, Conrado del Campo encontró un importante punto de desarrollo en su encuentro con el poeta Carlos Fernández Shaw. El libretista le ofreció un texto para transformar su música sinfónica en una ópera de fuertes resonancias tristanescas: La tragedia del beso, el más ambicioso proyecto musical dantesco de la música española.

\section{PAOLO Y FRANCESCA EN LA TRADICIÓN MUSICAL}

Durante el siglo XIX el mundo operístico había canalizado su interés hacia Dante poniendo sobre la escena numerosas versiones de la historia de Paolo 
y Francesca. Rossini cita los versos de Dante ("Nessun maggior dolore...”) en su Otello (I816) cantados a lo lejos por un gondolero ante la ventana de Desdémona, como un presentimiento de su trágico desenlace. Este doloroso canto fue utilizado por el propio Liszt en uno de sus números del cuaderno dedicado a Italia de Años de peregrinaje. Sin duda en esta utilización resonaba la fortuna de la tragedia Francesca da Rimini de Silvio Pellico (I8I5), sobre la que Felice Romani escribió un libreto de ópera en I823. Fue puesto en música por varios compositores italianos de la época, hoy poco conocidos (como Feliciano Strepponi, el padre de la mujer de Verdi), siendo la base de una interesante ópera de Mercadante que no se llegó a estrenar, compuesta durante su estancia en Madrid (Cascio 20I4).

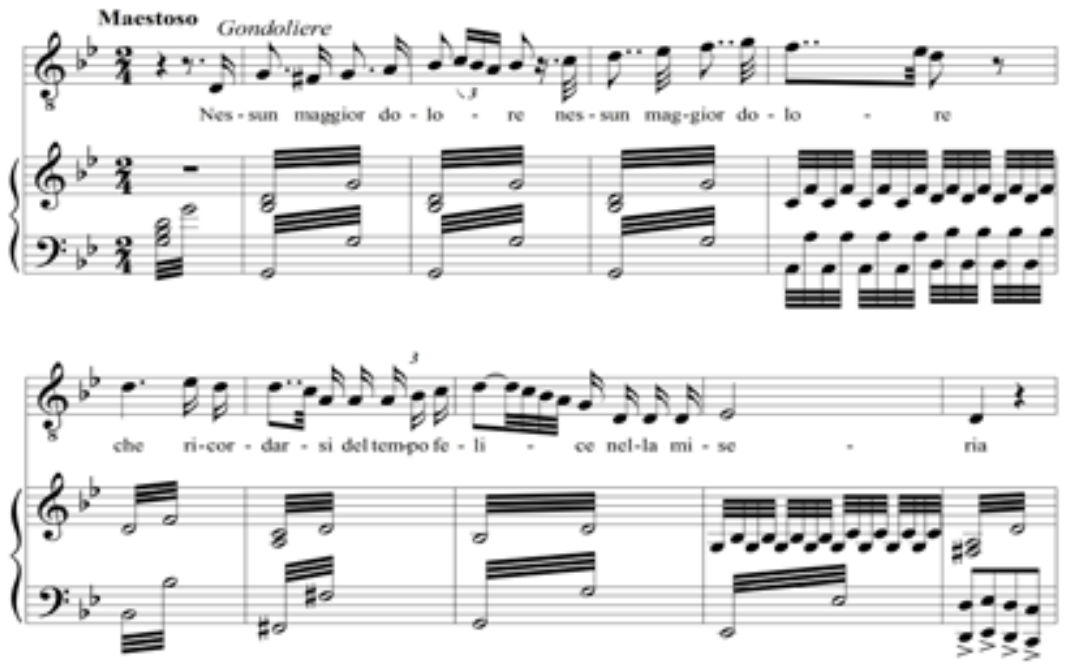

Fig. I. Rossini, Otello, acto III (canto del gondolero)

Con posterioridad, otros compositores italianos han ofrecido nuevas versiones operísticas de Francesca da Rimini. Antonio Cagnoni la utilizó para su última ópera, estrenada sin despertar mucho interés en I878 en el Reggio de Turín. Quizás lo más destacable era la colaboración con Antonio Ghislanzoni, el futuro libretista de Aida, que expandió el tema para incluir más personajes y episodios en una tragedia en cuatro actos (Dellaborra 1997). La edición del libreto se inicia con una breve nota citando la explicación de Giovanni Boccaccio en torno a la aventura de Francesca de Rimini. En el mundo italiano la versión más destacable es la de Riccardo Zandonai, con un libreto que seguía de cerca la tragedia de Gabriele D’Annunzio, adaptada por el editor Tito Ricordi. La delicada y sensual atmósfera del escritor italiano ofreció un 
elaborado melodrama, donde se equilibra la modernidad sonora - influida por Richard Strauss y Debussy - con la tradición vocal italiana (Chiesa 1965). Estrenada en Turín en 19I4, ha permanecido en el repertorio, frecuentada por grandes intérpretes como las sopranos Magda Olivero, Mirella Freni y Renata Scotto, o los tenores Franco Corelli y Plácido Domingo, entre otros muchos. En Madrid se estrenó en la inauguración de la temporada de ópera del Teatro de la Zarzuela en diciembre de 1926, siendo recibida con curiosidad, acusada de verista y efectista. El crítico Víctor Espinós destacó "la pintura sincera y cordial de los ambientes, teñidos de gracia, de suavidad y de trasparencias sonoras", especialmente en el primer acto (La Época, IO-XII-I926).

En el fondo del tema de Paolo y Francesca resuenan los ecos wagnerianos de Tristán e Isolda. Curiosamente, en el mismo círculo en que penan sus culpas los lussuriosi Dante incluye también al mismo Tristán: “... Vedi Parìs, Tristano'; e più di mille / ombre mostrommi e nominommi a dito, / ch'amor di nostra vita dipartille" (If. V 67-69). La paradójica relación de amor y muerte, como intensidad vital frente a la irracionalidad existencial, constituye uno de los ejes del Romanticismo explotado por todo el mundo operístico, que encuentra su máxima expresión en el famoso Liebestod que cierra el Tristán wagneriano. Sin duda, este modelo está presente en la mayoría de las versiones operísticas de Paolo y Francesca, muchas de ellas aparecidas en medio del intenso debate wagneriano de fin de siglo.

Un caso claro en este sentido es Paolo e Francesca de Mancinelli, cuyo estreno en 1907 en el Teatro Comunale de Bolonia estuvo precedido por quince funciones de Tristán, cantada en italiano como era habitual en aquella época (Mariani I998: 74-75, 254-255). Luigi Mancinelli (I848-I92I) fue conocido en su época sobre todo como director de orquesta, con una amplia carrera internacional, y fue también uno de los principales impulsores del wagnerismo tanto en Italia como en España, dirigiendo en el Teatro Real de Madrid los estrenos de Tannhäuser (I890) y Los maestros cantores (I893). Mancinelli utiliza para su Paolo e Francesca un libreto de Arturo Collauti, un autor que había tenido fortuna en la escena lírica con los textos para Fedora de Giordano (I898) o Adriana Lecouvreur de Cilea (1902). El libreto es muy conciso: un único acto centrado en los tres personajes principales y únicamente ambientado en la corte malatestiana de Rímini. Un modelo operístico que tenía difícil encaje en las programaciones líricas del momento, justificado por su fidelidad a las fuentes originales. Una advertencia en el texto publicado dejaba claras estas intenciones: "Nel comporre il presente drama lirico fu seguita unicamente la traccia del divino Poema, senza soverchi scrupoli di storica esattezza, volendosi serbare intatta ai due primarî personaggi la ideale purificazione, loro concessa per tutti i secoli avvenire dal sommo Dittatore dell'Arte" (Mancinelli, Colautti 1907: 7). De hecho, en la escena final, prolongando la agonía de los dos aman- 
tes que se funden en su eterno abrazo, se escucha un coro de voces lejanas que cita versos de Dante ("Amor che a cor gentil ratto s'apprende, / Amor che a nullo amato amar perdona", Mancinelli, Colautti 1907: 37).

La ópera de Mancinelli recorrió los principales teatros italianos siempre bajo la prestigiosa batuta de su autor, aunque sin mucha fortuna. Significativamente, en su estreno en Madrid en febrero de 1915 se rodeó de fragmentos wagnerianos: el preludio de Parsifal, la obertura de Tannhäuser y tras la ópera el preludio y muerte de Tristán. No obstante, el estilo musical de Mancinelli se movía entre las referencias wagnerianas y el canto italiano para la pareja protagonista de tenor y soprano. Augusto Barrado en el diario madrileño La Época comentaba: "Nadie podrá, sin incurrir en manifiesta inexactitud o ignorancia, tildar de wagneriana esta partitura, toda ella bañada de luz latina, pletórica de melodía genuinamente italiana" (La Época, 3-II-I9I5).

Más allá del mundo italiano, el tema de Paolo y Francesca ha tenido repercusión en otros ámbitos operísticos. En Francia, Ambroise Thomas estrenó Françoise de Rimini en la Ópera de París en I882, con libreto de Jules Barbier y Michel Carré. La ópera seguía las convenciones de la Grand Opéra con sus cinco actos (en realidad prólogo y cuatro actos con un breve epílogo), su espectacularidad escénica, sus números cerrados, sin que faltase el habitual ballet inserto al margen de la acción. Se trata así de una versión un tanto convencional, realizada por un compositor al final de su carrera anclado en su nacionalismo antigermánico desde su prestigioso puesto de director del Conservatorio. El estreno se retrasó, envuelto en una polémica provocada por la rivalidad entre los compositores franceses que buscaban el apoyo institucional a toda costa (Huebner 1999: 232). De hecho fue su última ópera, siendo acusado de nuevo de banalizar con los clásicos de la literatura universal, como ya había sucedido en sus anteriores éxitos: Mignon (I866, a partir de Goethe) y Hamlet (1868, a partir de Shakespeare). Un acercamiento circunstancial a Dante destinado al servicio de la espectacularidad superficial de la alta burguesía francesa.

En Rusia, el éxito de la fantasía sinfónica de Chaikovski reactivó el interés por el tema. En 1902 se estrenó en San Petersburgo Francesca da Rimini de Eduard Nápravník, el reconocido director de la orquesta del Teatro Imperial. Su versión adaptaba el drama Paolo and Francesca del escritor inglés Stephen Phillips, que había tenido gran éxito en la escena londinense. En sus cuatro largos actos presentaba la trágica historia de los amantes inserta en unas complicadas intrigas cortesanas, con numerosos personajes y episodios. Muy diferente fue la propuesta del compositor y pianista Serguei Rachmaninof, estrenada en Moscú en 1906. Su único acto enmarcaba la acción de la corte de Malatesta con un prólogo y un epílogo ambiental en el que se veía a Dante y el fantasma de Virgilio recorriendo los círculos del infierno, rodeados de las quejas de los condenados. 

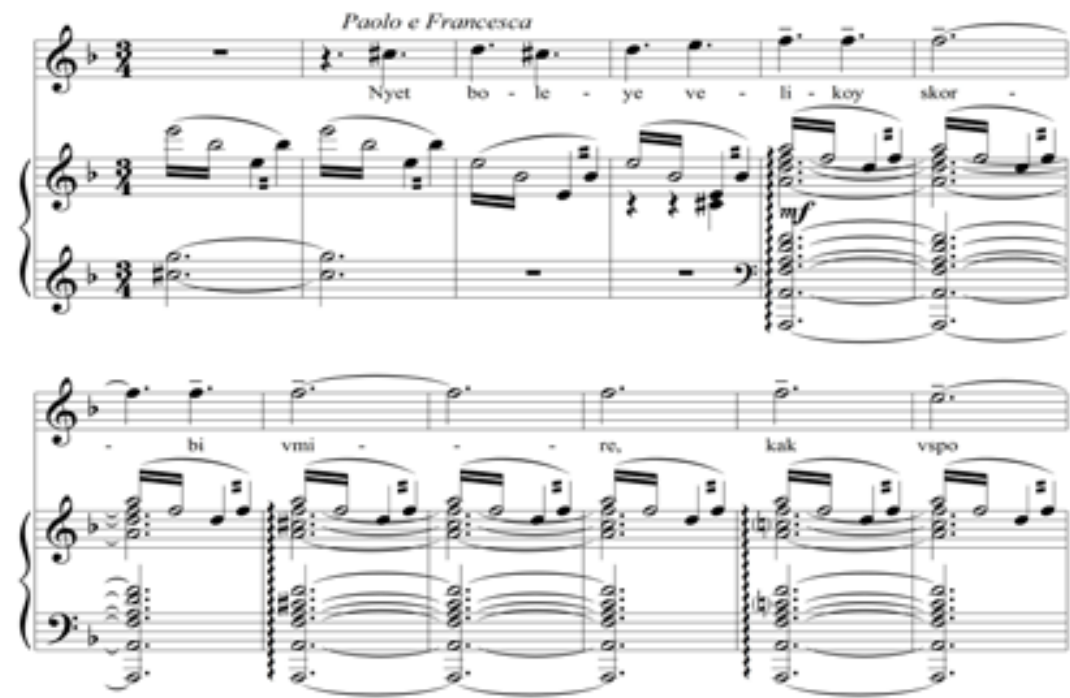

Fig. 2. Rachmaninof, Francesca da Rimini

La historia arranca con el famoso aforismo de Dante ("No hay mayor dolor que recordar los momentos felices en la miseria") que, como un coro distante, también cierra la ópera. De esta manera el libreto sigue más de cerca la Divina Comedia. Rachmaninof se lo encargó a Modest Chaikovski, el literato hermano del famoso compositor. Un texto muy conciso que apenas permitía una hora de música. Rachmaninof, con la inseguridad que siempre le persiguió, comentó al libretista:

Ahora que he terminado, puedo decirte que, mientras estaba trabajando, he sufrido sobre todo a causa de la brevedad del texto. Esto se nota más en la segunda escena, donde hay una construcción para el dúo de amor y una conclusión al dúo de amor, pero no hay realmente dúo. La brevedad de las palabras era aún más concisa porque no me suelo permitir repetir palabras. Aunque en Francesca me lo he permitido, solo en unas pocas palabras. La segunda escena y el epílogo duran veintiún minutos, lo que es terriblemente poco. En total la ópera dura poco más de una hora (Carta del 3 de agosto de 1904; Norris 1993: I33, la traducción es nuestra).

Francesca da Rimini de Rachmaninof es una ópera hermosa e interesante, a pesar de permanecer fuera del repertorio. Su prólogo describe con intensidad sinfónica el viaje de los poetas por el infierno sobre un lenguaje cromático y las vocalizaciones sin letra del coro, creando un sugestivo marco para el resto de la obra. Curiosamente, la escena más desarrollada iba destinada a Lanciotto, pensada para el gran bajo Fiodor Chaliapin, que podía lucirse expresando los tormentos psicológicos del personaje. 


\section{Conrado del Campo y La Divina Comedia}

El tema del Infierno de Dante, de tanta tradición musical en el siglo anterior, como hemos visto, despertó también el interés de Conrado del Campo (I878-1953), uno de los más interesantes músicos de su generación. Compositor prolífico, desarrolló una intensa actividad como instrumentista, tocando además la viola en la Orquesta Sinfónica de Madrid - dirigida por Arbós desde su fundación en 1904 y en el atril del foso del Teatro Real, desde I896 hasta su cierre de 1925. Así vivió intensamente desde dentro la actividad musical madrileña. No debe extrañarnos que su experiencia interpretativa sea decisiva en su creación, como comentaba Rogelio Villar: "Conrado del Campo [...] ha oído mucha música y, especialmente, muchas óperas, cuyas partituras conoce al detalle: en una palabra, Conrado del Campo conoce el teatro y esto le permite caminar con segura planta, sin vacilaciones, sin infantilismo, sin inexperiencias" (El Pais, 19-V-1915).

En este contexto surgen sus primeros proyectos operísticos: la zarzuela (sin duda de corte operístico por su ambición dramática y musical) La flor del agua, con libreto de Víctor Said Armesto (Villanueva 20II; 20I4), y la ópera El final de Don Álvaro, drama lírico en un acto con texto de Carlos Fernández Shaw, que reelaboraba el final del famoso drama del duque de Rivas. Compuesta durante el verano de I9IO, se estrenó en el Teatro Real en marzo de I9II, destacándose la valía dramática del compositor - hasta entonces sólo conocido por su música instrumental - y su fuerte wagnerismo (Sánchez 20IOa: I50I6I). Desgraciadamente, Carlos Fernández Shaw no pudo asistir al estreno de la ópera de Conrado del Campo, ya que se encontraba convaleciente de una enfermedad que le llevaría a fallecer tres meses después.

En 1908 estrenó el "prólogo instrumental de La Divina Comedia", conocido posteriormente como La Divina Comedia - Infierno, una pieza orquestal de carácter programático que representaba musicalmente el infierno de Dante. El crítico Cecilio de Roda nos da una buena descripción tras escucharla el día del estreno: "Tiene el color tétrico y sombrío que conviene a la selva selvaggia, aspera e forte; está tratado con elevación de pensamiento, con espíritu de vidente, en esa nebulosidad melódica que tanto caracteriza el estilo de este joven compositor" (La Época, 27-IV-1908). Su elevado cromatismo y densidad orquestal ofrecen una tensa recreación sonora del infierno dantesco, recogiendo a Liszt y Chaikovski junto al atrevimiento musical wagneriano. De hecho, estas piezas posicionaron definitivamente a Conrado del Campo como el compositor español más fuertemente wagneriano, una de las referencias del sinfonismo postromántico español, una vía que huye de las referencias nacionalistas en favor de la tradición centroeuropea. 
Dos años después estrenó una segunda pieza anunciada como "La divina Comedia, fragmento final del Infierno, canto XXXIV" (El Pais, I7-IV-I9Io). Con una sonoridad más tranquila describe la salida de Dante y Virgilio del infierno, la esperanzada vuelta a la luz, como dicen los últimos versos: "salimmo sù, el primo e io secondo, / tanto ch'i' vidi de le cose belle / che porta 'l ciel, per un pertugio tondo. / E quindi uscimmo a riveder le stelle." En los compases finales Conrado del Campo nos muestra su sensibilidad instrumental, difuminando las sonoridades en la distancia hacia el agudo de las maderas y los armónicos en la cuerda.

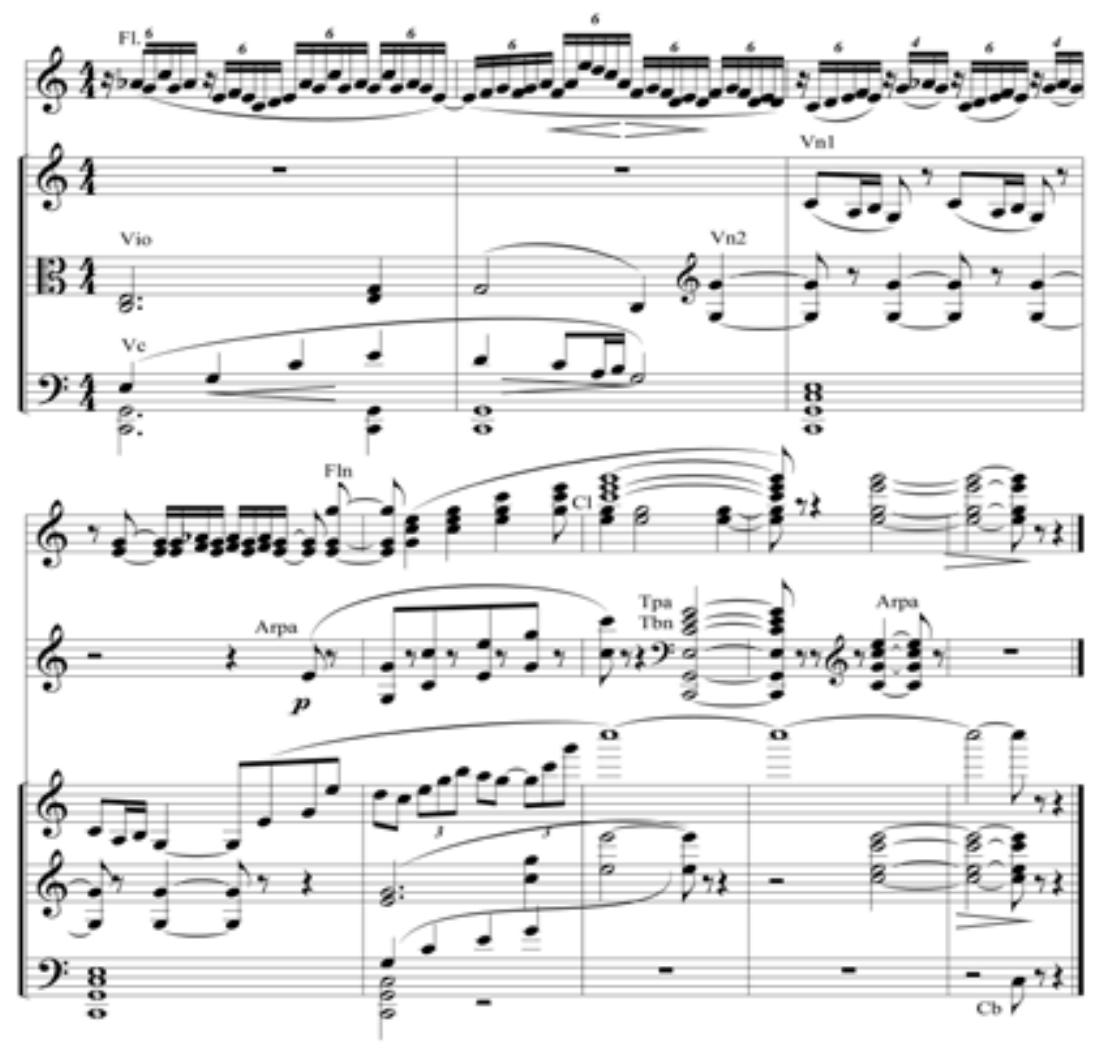

Fig. 3. Conrado del Campo, La Divina Comedia: El Infierno, Final

El crítico Manrique de Lara comentó con entusiasmo que la segunda parte era "la más hermosa entre todas las composiciones de su autor y una de las más afortunadas de que puede envanecerse la moderna producción musical española” (El Mundo, I8-IV-I9Io). Ambas piezas fueron estrenadas por la Orquesta Sinfónica de Madrid bajo la dirección de Enrique Fernández Arbós, en 
los breves ciclos que realizaban en el Teatro Real; unos conciertos que mezclaban fragmentos wagnerianos con sinfonías de Beethoven y Mozart. El propio autor permaneció en su atril de las violas, saliendo a saludar al final de la interpretación. La prensa destacó el dominio técnico del joven compositor, llegando a calificarle como "uno de los músicos más intelectuales y soñadores que poseemos" (El País, I9-IV-i9io).

En los años siguientes, La divina comedia de Conrado del Campo se incorporó al repertorio de la Orquesta Sinfónica, siendo repetido en otros ciclos e interpretado durante sus giras por España en Zaragoza y Granada. Un caso especial fue su inclusión en el programa que la propia Sinfónica de Madrid interpretó en el Teatro de los Campos Elíseos de París en octubre de I9I3. La obra de Conrado del Campo reflejaba la variedad estilística de la creación española contemporánea, junto a piezas más españolistas como la Suite murciana de Pérez Casas o La procesión del Rocio de Turina (El Imparcial, 30-X-1913). Fernández Arbós ofreció la obra en otros países, incluyéndola en San Petersburgo (Revista Musical de Bilbao, enero I9I2) y Roma. Como era habitual, la ausencia de nacionalismo provocaba un cierto desinterés ante un público que buscaba más el tópico de lo español; en este sentido un cronista escribía desde la capital italiana:

Ya puede suponerse que los mayores elogios y las ovaciones más nutridas han sido para aquellas obras que más plenamente respondían al concepto que de nuestra música se tiene en el extranjero. Así, mientras el hermoso poema sinfónico de Conrado del Campo y las exquisitas Escenas de niños de Oscar Esplá sólo merecieron el placet del auditorio, no obstante su mérito considerable, superior a muchas geniales banalidades que dan la vuelta al mundo bajo pabellón ruso, alemán o francés, la unanimidad de sufragios y el aplauso más cálido fueron para el Polo gitano de Bretón [...] y La Procesión del Rocio de Turina (Revista Musical Hispano-Americana,febrero I9I5).

\section{LA TRAGEDIA DEL BESO, POEMA DRAMÁTICO de Carlos Fernández ShaW}

Una de las versiones más interesantes de la historia de Paolo y Francesca en la literatura española es el drama La tragedia del beso, poema dramático escrito por Carlos Fernández Shaw en i910. Estructurado en un acto único en tres cuadros, el primero presenta a Dante y Virgilio llegando al infierno, donde encuentran entre lamentos de los condenados a Paolo y Francesca; después, un súbito cambio de decorado nos lleva a la corte medieval italiana para ver su trágica historia de amor, en la que fueron sorprendidos por Lanciotto Malatesta y murieron atravesados por una espada que les condenaba a estar siempre unidos; finalmente, un breve cuadro final nos devuelve al infierno, donde 
vemos cómo los dos poetas se alejan. La obra fue escrita para la actriz María Guerrero, que la estrenó en su beneficio del Teatro de la Princesa en marzo de I9IO, en una función en que se incluía además una comedia de los Quintero y un poema de Ángel Guimerá. Dicho teatro madrileño (que actualmente lleva la denominación de la famosa actriz y es sede del Centro Dramático Nacional) se había convertido en un local para público selecto de alta burguesía y aristocracia, huyendo del populismo y la masificación de los numerosos locales dedicados a la comedia y al género chico. Se trataba así, no de una obra comercial, sino de un producto cultural elitista, lleno de referencias a uno de los clásicos de la literatura universal. En este sentido, tras el estreno, el crítico madrileño que firmaba como Alejandro Miquis "reivindica el Teatro para la Poesía”, un teatro lírico basado en el verso más que en la acción:

Quizás fuese bueno que al Teatro poético llegásemos evolutivamente, que los poetas labrasen ahora un terreno de transición, en que el Teatro monócromamente insustancial, grato al público porque no le pide hiperexcitación de su sensibilidad ni acción activa de su pensamiento, sirviera de base al Teatro, más noble y alto, todo poesía, que sońamos. (Diario Universal, I5-III-1910)

Sin duda, esta era la postura en que trabajaba Carlos Fernández Shaw. Su vena poética la compatibilizaba con una obra dramática llena de referencias metaliterarias, como en el sainete Las bravias (basado en La fierecilla domada de Shakespeare), la zarzuela cómica La venta del Quijote o la ópera El final de don Álvaro. En todas estas propuestas, surgidas en contextos muy diversos, subyace un interés de actualizar y reflexionar sobre el pasado literario, forzando el trasvase entre géneros e idiomas.

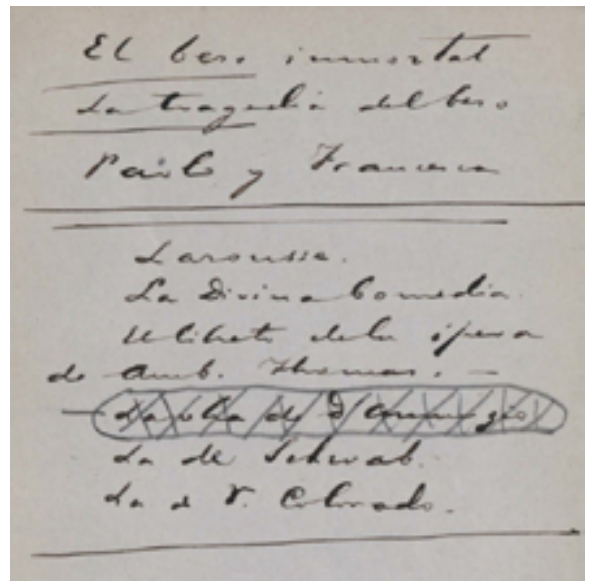

Fig. 4. Carlos Fernández Shaw, nota manuscrita con el listado de fuentes. Biblioteca Fundación Juan March, CFS-68A. 
En La tragedia del beso toma como punto de partida el canto V del Infierno de la Divina Comedia, el recorrido por el segundo círculo y su encuentro con Paolo y Francesca. En una nota manuscrita conservada entre los planes y bocetos de la tragedia, el autor anota las fuentes consultadas: el diccionario Larousse, la propia obra de Dante, el libreto de la ópera francesa de Ambroise Thomas; también incluye en el listado "la obra de D'Annunzio", aunque tachándola, "la de Schwob" y "la de V. Colorado".

La última versión hace referencia a Francisca de Rímini de Vicente Colorado, un poco inspirado drama en tres actos escrito en 1885 , seguramente no estrenado, que además de espańolizar los nombres (Juan Malatesta, Pablo y Francisca) introducía al personaje de Dante como testigo de la trágica historia de los amantes. Pero sin duda la fuente principal es la tragedia Francesca da Rimini de Francis Marion Crawford, escrita en inglés pero traducida al francés por su amigo Marcel Schwob en I902. Fernández Shaw estudió a fondo esta versión, existiendo en su legado hojas con listados a lápiz de números de páginas y copias de citas del drama en francés. Crawford era un escritor estadounidense que había vivido mucho tiempo en Italia y que pretendía ofrecer con este texto una documentada versión de la tragedia, "fundado en los acontecimientos reales y los datos históricos". En la edición del drama se incluye un extenso prólogo donde el autor narra sus investigaciones en Verucchio (la escarpada villa próxima a Rímini en cuyo castillo sucedió la historia), valorando la fiabilidad de las fuentes; además incluye la cita del canto V del Inferno (con su traducción al francés), los comentarios de Boccaccio y biografías de Giovanni y Paolo Malatesta. El largo drama (en cinco actos incluido un prólogo con los precedentes) se centra en la tragedia de Paolo y Francesca y todas las intrigas cortesanas que les rodean. No presenta - como hará Fernández Shaw - el recorrido de Dante y Virgilio por los círculos del infierno. De hecho, el poeta encabeza estas anotaciones como "escena grande", en referencia al cuadro central de su poema dramático.

La tragedia de Crawford iba destinada a Sarah Bernhardt, con quien había ya colaborado en anteriores ocasiones. El estreno se produjo así en el teatro parisino que lleva su nombre en abril de 1902. Como era habitual, la famosa actriz - interpretando el papel de Francesca - era el centro de la producción y tenía una parte muy destacada en el texto. Esta moda de grandes intérpretes dramáticas estaba en plena actualidad en el fin de siglo, con figuras como la italiana Adelaide Ristori o en el caso español la propia María Guerrero. Estas

I. La tragedia del beso, original manuscrito a lápiz y tinta con correcciones y paginado, Madrid, Biblioteca de la Fundación Juan March, Legado de Carlos Fernández Shaw, CFS-68-Ao4. Al comienzo de la misma nota añade dos alternativas al que sería el título definitivo: El beso inmortal, Paolo y Francesca. El documento aparece mal catalogado, ya que no se trata del original manuscrito de la obra, sino de un borrador en prosa y diversas anotaciones. 
grandes actrices buscaban papeles complejos con los que lucirse en una gran variedad de registros. Resultaba bastante evidente que la española pretendía emular los éxitos de la mundialmente reconocida Sarah Bernhardt. De hecho, Fernández Shaw en La tragedia del beso desarrolló el papel de Francesca, introduciendo el personaje en el prólogo infernal como un espíritu que dialoga con los poetas, aunque su momento central era un extenso monólogo en el segundo cuadro en el que expresa su amor y sus dudas. Lógicamente, toda la prensa destacó la participación de María Guerrero, que "pone en su papel tanta pasión y tan ingenua delicadeza, que el público aplaudió entusiasmado" (España Nueva, I5-III-I9Io).

El poético drama de Fernández Shaw estaba destinado a un beneficio puntual de María Guerrero, por lo que, más allá de esa función especial, tuvo poca difusión. La propia actriz lo llevó en su gira inmediata, primero en abril en Sevilla y Cádiz, ${ }^{2}$ y luego en Argentina ese mismo verano, representándolo en el Teatro Odeón (julio de 1910) y en el Colón de Buenos Aires (agosto de I9IO), según se puede ver en dos carteles conservados en el legado del escritor. ${ }^{3}$ Las funciones de Cádiz siempre eran especiales, ya que era la ciudad natal del autor; en el Diario de Cádiz se comentó el interés de la nueva tragedia de su ilustre paisano:

La tragedia del beso es una poesía en acción. Es la exteriorización de los versos del poeta convertidos en tangibles, con algún mejor fondo que el monótono matiz blanquecino de las páginas de un volumen. Mirado bajo este punto de vista, el intento de implantar la poesía bajo los doseles de un decorado espléndido realizado por nuestro ilustre paisano ha sido un doble éxito teatral y dramático (Diario de Cádiz, 26-IV-I9IO).

La tragedia del beso es así, ante todo, un teatro poético, un teatro donde el centro del espectáculo estaba en la declamación del verso. Carlos Fernández Shaw era un hábil poeta, recogiendo la intensidad romántica de manera controlada, como en Poesía de la Sierra (1908) o Poesía del mar (1910). La crítica, como era habitual en sus estrenos, también destacó esta capacidad versificadora:

¿Cómo realizó sus propósitos Carlos Fernández Shaw? Con discreción y con un verso abundante y sonoro, sobre todo, sonoro. Fernández Shaw es un poeta sonoro; sus versos no se limitan a darnos un reflejo de un estado del alma, sino que pretenden convencer al auditorio, y digo auditorio, porque aún la poesía lírica de Fernández Shaw es para recitada (El Mundo, I5-III-I9IO).

2. Véase el cuaderno de recortes de prensa recopilado por el propio autor. Carlos Fernández Shaw: cuaderno 23 (I910), Madrid, Biblioteca de la Fundación Juan March, Legado de Carlos Fernández Shaw, CFS-23.

3. Cartel del Teatro Colón de Buenos Aires (CFS-AE XX 49) y programa de mano del Teatro Odeón de Buenos Aires (CFS-AE XX 53), Madrid, Biblioteca de la Fundación Juan March, Legado de Carlos Fernández Shaw. 
Uno de los mejores logros de La tragedia del beso es el primer cuadro, con su visión del infierno y el encuentro con los penados. Como hemos visto, no era habitual en la mayoría de las versiones, con la excepción de la tópica presentación en la ópera de Thomas. El poeta español recrea de forma escenificada el canto $\mathrm{V}$ del Infierno, incluyendo referencias directas a los propios versos de Dante, que señala en la edición con cursiva. Un breve ejemplo de la escena II (cuando Dante se dirige a la pareja condenada) puede mostrar esta idea de recreación del texto original:

\begin{tabular}{|c|c|}
\hline $\begin{array}{l}\text { FRANCESCA: } \\
\text { Ser compasivo y bienhechor, -iquien seas!- } \\
\text { Tú que en las sombras de la eterna noche } \\
\text { que ve mi angustia, con amor nos hablas, } \\
\text { y nos acoges con amor: ¿quién eres? }\end{array}$ & \\
\hline $\begin{array}{l}\text { PAOLO: } \\
\text { Tú, que dulce nos llamas, - a nosotros } \\
\text { que en sangre el mundo, con horror, teñimos;- } \\
\text { si el Rey del Universo nos amara, } \\
\text { pidiéramos por ti, por la ventura } \\
\text { de tu reposo eterno. ¡Bien merece } \\
\text { noble reposo quien nació tan noble! }\end{array}$ & $\begin{array}{l}\text { noi che tignemmo il mondo di sanguigno, } \\
\text { se fosse amico il re de l'universo, } \\
\text { noi pregheremmo lui de la tua pace, } \\
\text { (If. } \mathrm{V} 9 \mathrm{9-92)}\end{array}$ \\
\hline $\begin{array}{l}\text { DANTE: } \\
\text { Salud, ¡oh, sombras trágicas!, ¡oh víctimas } \\
\text { del amor desdichado! }\end{array}$ & \\
\hline $\begin{array}{l}\text { FRANCESCA: } \\
\text { ¡Tú nos amas! }\end{array}$ & \\
\hline $\begin{array}{l}\text { PAOLO: } \\
\text { No dudes, no receles. ¿̨ue tan sólo } \\
\text { culpa de amor nuestra vitanda culpa! } \\
\text { (Pausa breve) }\end{array}$ & \\
\hline $\begin{array}{l}\text { FRANCESCA: } \\
\text { Ningún dolor en su dolor más grande } \\
\text { que el evocar, en tiempo de miseria, } \\
\text { las bienandanzas del pasado tiempo. }\end{array}$ & $\begin{array}{l}\text { E quella a me: "Nessun maggior dolore } \\
\text { che ricordarsi del tempo felice } \\
\text { ne la miseria; e ciò sa 'l tuo dottore." } \\
\text { (If. V I2I-I23) }\end{array}$ \\
\hline
\end{tabular}

Pero La tragedia del beso iba mucho más allá que un texto poético dramatizado, planteando una efectista puesta en escena. En primer lugar la ambientación del infierno que recorren los poetas con las voces de los condenados a lo lejos; según la edición era una "decoración fantástica, iluminada por amplios y movibles reflejos rojos". Es decir que la iluminación jugaba un papel fundamental, tal como nos describen algunas crónicas del estreno: "Se queda el 
teatro a oscuras. El escenario cuando se alza el telón, está iluminado de una luz roja. Es más, se siente un calor especial; como que estamos en el infierno" ( $E l$ Mundo, I4-III-I9IO). Otro momento destacado era el cambio de cuadro, en que se pasa de las oscuridades infernales al jardín del castillo de Verucchio; la descripción del libreto resulta muy elocuente: "La selva es hermosa; con altos árboles y profusas plantas. Abril la ha engalanado llenándola de flores. Luce el cielo tonos radiantes. El sol primaveral esplende magnífico, pero en la vaga lejanía se cierne un nublado tempestuoso, que al cabo desaparecerá." Una vez más este rápido cambio, todo un golpe de efecto teatral, sorprendió agradablemente al público: "Las decoraciones y las ilustraciones musicales dieron relieve a la obra, que no es fácil de poner en escena porque exige dos rápidas mutaciones. Y fue de aplaudir el ingenio de luz que permite transformar la escena del Infierno en la de un jardín florido en medio minuto, sin echar el telón y sin que el espectador pueda enterarse de las maniobras" (El Mundo, I5-III-I9Io).

La música se sumaba a esta ambientación. Como en la mayoría de los teatros de declamado, el Teatro de la Princesa tenía un pequeño conjunto instrumental que subrayaba las representaciones. Más que una orquesta, solía ser un grupo de cámara, frecuentemente un sexteto formado por un quinteto de cuerda, una flauta o un clarinete, aunque no tenemos información de cómo era el conjunto que acompañó el estreno de La tragedia del beso. Además de tocar alguna pieza para la entrada del público, a modo de sinfonía, solían apoyar los momentos claves de las obras representadas. En el texto hay algunas indicaciones en este sentido, como al inicio: "Una orquesta oculta deja oír brevísimo preludio. Descubre el telón el cuadro ya descrito y aún sigue sonando la música hasta el momento que más adelante se fija." Entre las notas y borradores manuscritos del autor ya mencionados ${ }^{4}$ se encuentra una interesante nota doblada en la que se precisan las músicas utilizadas y el lugar que ocupan en la representación:

I) En la escena del infierno suena la "Suite de Grieg p. 46, La mort d'Ase", uno de los movimientos de la música incidental que compuso el compositor noruego Edvard Grieg para Peer Gynt de Ibsen, un fragmento muy popular en conciertos y veladas musicales. Se trata de un delicado Andante doloroso, originalmente para la cuerda con sordina, que en el drama de Ibsen acompañaba el momento en que el protagonista asiste a la muerte de su madre. Por las indicaciones de la mencionada nota manuscrita, en La tragedia del beso sonaba al comienzo desde "antes de levantarse el telón" y al final del cuadro para el cambio escénico. La vuelta al infierno en el último cuadro retomaba la misma música: "Al final del canto segundo empieza la música del infierno y dura hasta el final del poema."

4. La tragedia del beso, original manuscrito a lápiz y tinta con correcciones y paginado, Madrid, Biblioteca de la Fundación Juan March, Legado de Carlos Fernández Shaw, CFS-68-Ao4. 
2) El otro fragmento es el "Adagio cantabile del septimino de Beethoven", es decir, el segundo movimiento del Septeto para vientos y cuerdas en Mi bemol mayor op. 20. Este lírico movimiento lento, con un su hermoso diálogo entre el violín y el clarinete, acompańaba brevemente el inicio de la escena VI del cuadro segundo en el mencionado jardín y todo el monólogo de Francesca (escena VII), uno de los momentos centrales de la obra y de mayor lucimiento para María Guerrero. Sin duda, la intensa recitación de los versos en que la protagonista expresa su amor se veía realzada con este fondo musical. La calmada melodía del clarinete se unía a la exaltación de la primavera de Francesca: "Primavera / placentera; / bosque en flor; / ipara hechizarle, quisiera / vuestro encanto seductor!"

Estos dos fragmentos musicales, que seguramente seleccionó el propio Carlos Fernández Shaw, ${ }^{5}$ estaban muy alejados de la tradición musical romántica de Dante iniciada por Liszt, en especial los tensos desgarros sonoros con que se representaba el infierno. La elección del Andante de Grieg ofrecía un fondo sonoro tranquilo, doloroso y lleno de melancolía, mientras que el de Beethoven era un hermoso fondo para los versos. Como veremos estaban también lejos de la propuesta wagneriana de Conrado del Campo, cuando convierte en ópera el poema dramático de Carlos Fernández Shaw.

\section{LA ÓPERA LA TRAGEDIA DEL BESO}

Sin duda, todo el trabajo en La Divina Comedia de Conrado del Campo despertó el interés de su amigo y colaborador Carlos Fernández Shaw. El trabajo sinfónico llevó al gaditano a escribir La tragedia del beso y ambos hablaron mucho sobre Dante en los primeros meses de igro en medio de los preparativos del estreno, mientras el compositor terminaba la segunda parte de su Infierno. En abril el poeta asistió al estreno sinfónico: en una carta el músico le envía un palco para que asistiese al concierto. ${ }^{6}$ Poco después ambos trabajaron en El final de Don Álvaro y, una vez estrenada, emprendieron el trabajo de su siguiente ópera durante el verano de I9II, concluyendo la partitura de $L a$ tragedia del beso en noviembre de ese mismo año. ${ }^{7}$

Carlos Fernández Shaw es un autor fundamental para la ópera española, habiendo escrito los libretos de las principales propuestas de esta época, como La vida breve de Manuel de Falla, El certamen de Cremona de Tomás Bretón, Colomba de Amadeo Vives o La maja del rumbo de Emilio Serrano, además

5. En la edición de la tragedia (p. 4I) se incluye la siguiente aclaración: "Nota importante: El autor facilitará, gustosísimo, todas las indicaciones precisas para la parte musical de esta obra."

6. Carta de Conrado del Campo a Carlos Fernández Shaw, I7-IV-I9ıo (Biblioteca de la Fundación Juan March, Legado de Carlos Fernández Shaw, CFS-AE-XIV 28).

7. Conservada en el Fondo "Teatro Lírico" de la Sociedad General de Autores (Referencia: $\mathrm{MPO} / 3 \mathrm{IO})$. 
de las primeras óperas de Conrado del Campo (Guillermo Fernández-Shaw 1969; Lozano 1962). Su relación con Chapí resultó clave en este sentido, al ser uno de los más prolíficos colaboradores del músico de Villena. Según Luis G. Iberni, de la colaboración entre Chapí y Fernández Shaw salieron "a la escena madrileńa algunas de las aportaciones de mayor calado en la historia de la zarzuela" (Iberni 1995: 23I). Referencia fundamental es su aportación al sainete lírico madrileño, en colaboración con el castizo López Silva, con títulos de referencia como La revoltosa, Las bravias o La chavala, aunque también libretos cómicos más ligeros, como El triunfo de Venus (junto a Muñoz Seca) o El maldito dinero (junto a Arniches), y proyectos más elaborados, como $E l$ cortejo de la Irene o La venta de don Quijote, e incluso propuestas de zarzuela grande histórica en Los hijos del batallón. Pero sin duda su gran proyecto sería la ópera Margarita la tornera, estrenada con enorme éxito en el Teatro Real en 1909, que tuvo una fuerte repercusión y llevó a que se afirmase que por fin existía la ópera española.

La labor literaria de los libretos operísticos de Carlos Fernández Shaw ha sido discutida en diversas ocasiones. Su obra poética mantenía la grandilocuencia romántica decimonónica, como se puede ver especialmente en sus últimos libros de poemas, donde formalmente conserva las formas métricas tradicionales. ${ }^{8}$ Esta vena poética no resultó siempre adecuada para sus textos operísticos, especialmente cuando no existía un colaborador que colocase sus versos en el adecuado contexto dramático. Julio Gómez, al analizar el problema del libreto en la ópera española, lamentaba en Carlos Fernández Shaw la "expresión verbal demasiado abundante, a la que le llevaba su exuberante temperamento", particularmente en los libretos para Conrado del Campo, donde "se hace patente la falta de disciplina, la total carencia de formas producida por el abandono de las consagradas por el uso en la ópera tradicional y no hallar las concretas del drama lírico moderno con las que habría que haberlas sustituido" (Gómez 1956). En una línea similar, Miguel Salvador criticó tras el estreno de El final de Don Álvaro que uno de los principales problemas de la ópera española era que "no tenemos quienes produzcan libretos, tales como las corrientes crítico-musicales modernas los exigen", mencionando como modelo los dramas de Maeterlinck, cuyo estilo estaba muy alejado de los textos de Fernández Shaw: “¡Estos [poemas] pueden inspirar dramas líricos modernos, los que nosotros producimos no! Eso de explicar los antecedentes del drama es lo que nos mata, pues explicamos mucho los dramas y no ocurren ni suceden ellos; no tenemos en cuenta lo que debe de callar la letra, lo que debe traducir

8. Además de las ediciones originales, existen dos interesantes recopilaciones de la obra poética de Carlos Fernández Shaw: El canto que pasa: antología poética (I883-I9II) (Madrid, M. Aguilar, 1947) con prólogo de su hijo Guillermo Fernández-Shaw, y Poesías completas (Madrid, Gredos, 1966) con introducción y estudio de Melchor Fernández Almagro. 
y lo que no puede traducir la música; conocen nuestros poetas preciosamente el lenguaje hablado, ¡el musical para ellos es un arcano!..." (Revista Musical de Bilbao, abril I9II).

El encuentro de Carlos Fernández Shaw con Conrado del Campo surgió en el entorno de Chapí, músico con el que ambos colaboraron manteniendo una gran amistad y admiración profesional. Ambos siguieron muy de cerca los ensayos y el éxito de la ópera Margarita la tornera, que parecía abrir el camino de la ópera nacional. Como hemos visto, pronto colaboraron en la ópera El final de don Álvaro, tras cuyo estreno emprendieron el trabajo de una nueva ópera: La tragedia del beso. Para el libreto, trabajó directamente sobre el texto del poema dramático. En el legado del compositor se ha conservado una edición de la tragedia con algunas correcciones, tachaduras y anotaciones musicales del propio Conrado del Campo, lo que nos muestra su fidelidad al original, del que mantuvo los mismos versos cortando algunas escenas secundarias. El único añadido fue la aparición de un pastor al inicio del segundo cuadro, un acertadísimo efecto escénico que servía - según señala Adolfo Salazar - "para preparar de una manera delicada y bellísima la transición del ambiente trágico del cuadro primero a la gozosa escena siguiente" (Arte musical, junio 1915). Seguramente, estos cambios se realizaron bajo la supervisión del propio Fernández Shaw, su amigo y colaborador, aunque la grave enfermedad del poeta - que fallecería en junio de I9II - obligó al propio Conrado del Campo a colocar en su ópera algunos versos propios.

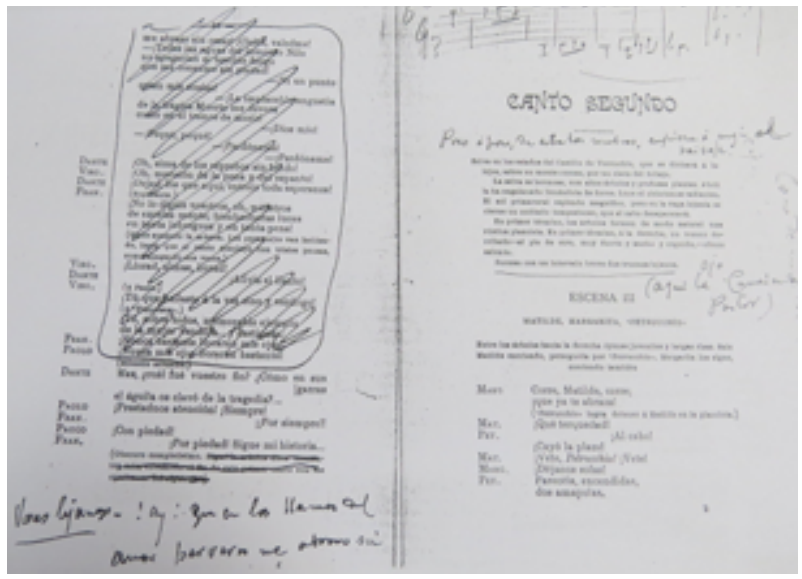

Fig. 5. Conrado del Campo, copia revisada de La tragedia del beso, pp. I6-I7

La tragedia del beso surge en un contexto fuertemente wagneriano. Debemos recordar la fiebre wagneriana que se vive en Madrid, que encuentra su punto culminante con la fundación de la Sociedad Wagneriana y el estreno en el 
Teatro Real de Tristán e Isolda en febrero de I9II (Sánchez 20Iob). Ya hemos mencionado anteriormente el paralelismo entre la historia de Paolo y Francesca y la de Tristán, y cómo el propio Dante situaba a Tristán en el mismo círculo del Infierno. Además, el planteamiento escénico resultaba similar al ideado por Wagner, teniendo su episodio principal en la declaración de amor (el momento del beso) a través de un largo e intenso dúo de la pareja protagonista que es interrumpido bruscamente por la aparición del marido engañado, que precipita el desenlace y la destrucción. Así, el tema central se mueve en los mismos ejes temáticos wagnerianos: el amor como fuerza irrefrenable y a su vez como fuerza destructora. La similitud tristanesca era llevada en La tragedia del beso hasta el nivel del detalle, incluyendo al comienzo del segundo cuadro una canción de un pastorcillo precedida de un solo del saxofón contralto, un episodio que recordaba inevitablemente al del pastor en el desesperanzado inicio del tercer acto del Tristán wagneriano con su triste solo de corno inglés.

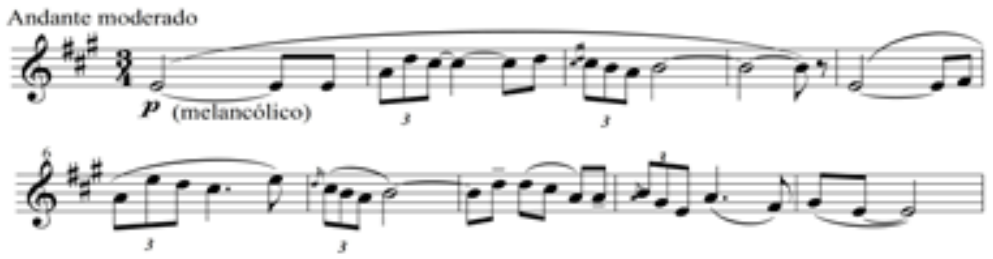

Fig. 6. Conrado del Campo, La tragedia del beso, inicio del cuadro $2^{\circ}$

Algunos críticos censuraron un detalle tan evidente, aunque Adolfo Salazar - comprendiendo los valores musicales de la nueva ópera de Conrado del Campo, que calificó como "una verdadera obra maestra" - defendió su originalidad, censurando con ironía la obsesión de los críticos por buscar influencias en todos los estrenos españoles:

Hasta tal punto llegan a afinar la puntería esos "cazadores de reminiscencias", bautizados así graciosamente por Weingartner, y hasta tal grado de obsesión llegan los amantes de descubrir parentescos, que hoy en día es imposible hacer oír una frase en la tuba sin que se exclame inmediatamente: 'Wagner', o emplear un pedal de contrafagot sin gritar 'Strauss', ni sentar dos amantes en un banco sin que se piense en Tristán, ni hacer sonar un caramillo campestre sin referirse al solo de corno del tercer acto de esa incomparable creación wagneriana. Solo así se concibe que se haya podido comparar musicalmente la canción del pastor de La tragedia del Beso, con ese momento homólogo al de Tristán; sin parar mientes en los significados opuestos de ambas situaciones dramáticas, sin detenerse a pensar que mientras nacía uno de esos casos [Tristán] como flor dolorosa en el ambiente de la melancolía y de tristeza, acentuando con su matiz de desesperanza los trágicos tonos de la obra, en La tragedia del Beso tenía una misión absolutamente distinta: la de disipar el efecto tétrico del prólogo y preparar sin brusquedad la escena posterior (Arte Musical 2I-V-I9I5). 
A pesar de este comentario, La tragedia del beso se inspiraba de una manera muy directa en el lenguaje musical del Tristán wagneriano. La escritura cromática servía para caracterizar tanto el ambiente desesperanzado del infierno como la intensa pasión amorosa de la pareja protagonista. Además, la gran actividad orquestal y polifónica nos remite a las activas texturas wagnerianas. Un buen ejemplo lo encontramos en la llegada de Dante y Virgilio, cuando los dos poetas leen la fatídica inscripción que franquea el infierno (el famoso "Lasciate ogne speranza, voi ch'intrate" traducido por el poeta español como "Dejad los que aquí entréis toda esperanza").
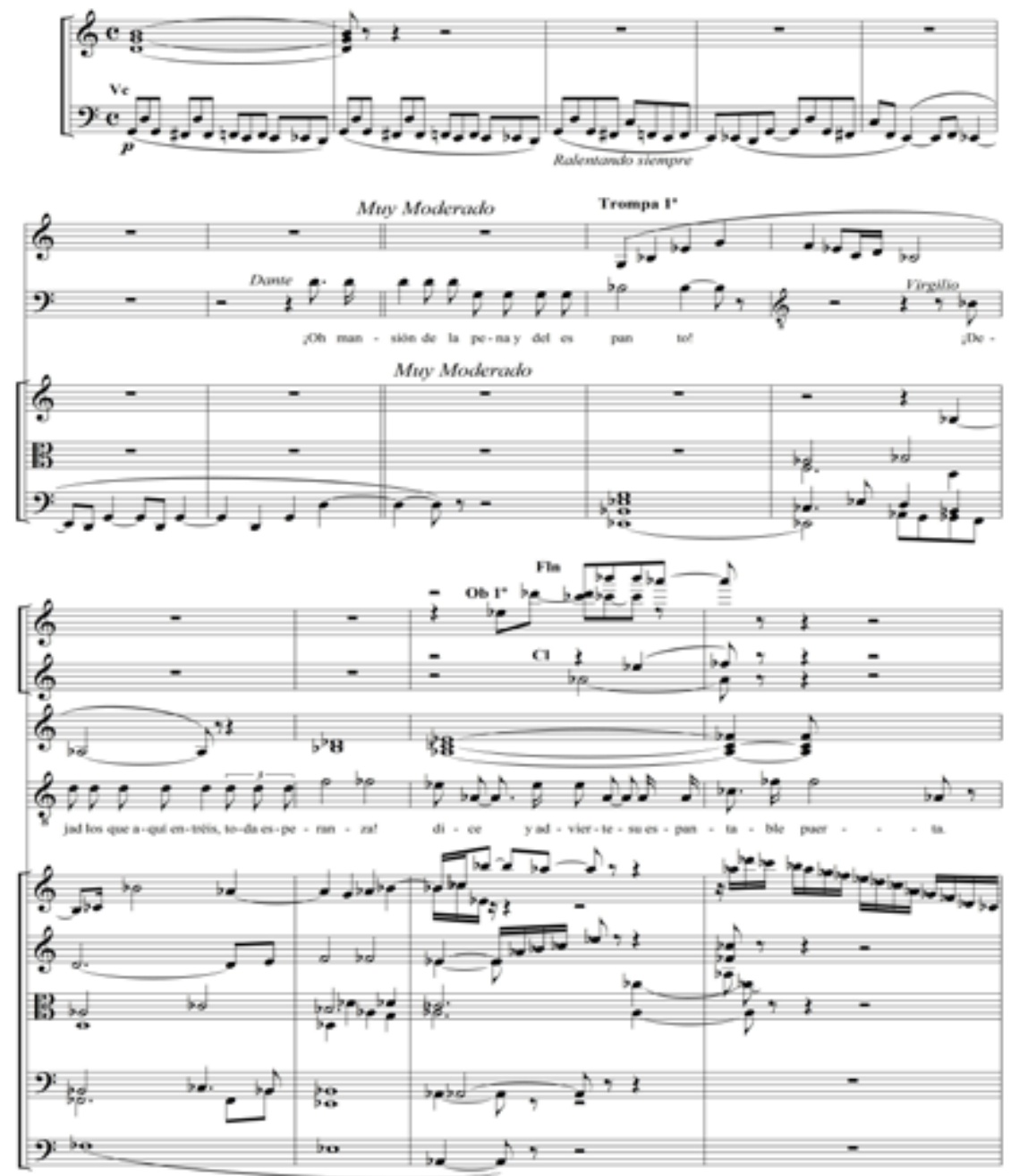

Fig. 7. Conrado del Campo, La tragedia del beso, cuadro $\mathrm{I}^{\mathrm{o}}$ 
El tema inicial - un amplio solo de los violonchelos - se va ralentando progresivamente a manera de recitado, ofreciendo una rica fluctuación cromática. Armónicamente también podemos apreciar una gran actividad, que contribuye a caracterizar la ansiedad con que Virgilio lee la famosa inscripción de entrada al infierno, mediante giros de tercera y enlaces cromáticos. A esto se une su gusto por las texturas densas y una actividad orquestal contrapuntística. En una carta a su discípulo Ángel Barrios le recriminaba que su "orquestación está bien dispuesta pero peca de excesivamente sobria, tenue, temerosa, débil. Para el resto, sobre todo, es preciso instrumentar con más robustez, con más cuerpo. Conviene también cuidar más el color buscando efectos de sonoridad, con más decisión, sin timideces." "Todos estos recursos armónicos nos remiten a la intensa expresividad del cromatismo wagneriano.

El carácter sinfónico de la partitura resulta evidente en la continua actividad instrumental que acompaña a las voces con un denso tejido de Leitmotiven. En el ejemplo anterior aparecen dos de los más significativos: un lírico arpegio (en la trompa $\mathrm{I}^{\mathrm{a}}$ ), que representa la nobleza y majestuosidad de los poetas, y una tensa apoyatura (en oboes y flautín), adecuada para reflejar las tensiones del infierno. Además, en el drama se insertan algunos pasajes puramente orquestales que servían para articular poéticamente la obra, como un anhelante preludio inicial o la transición hacia el segundo cuadro, con el mencionado solo de saxo. De hecho, la música del tercer cuadro incorpora casi de manera literal el segundo poema sinfónico El Infierno, lógicamente con algunos pequeños ajustes para la incorporación de las partes vocales. ${ }^{\mathrm{IO}} \mathrm{Se}$ conseguía así un cuadro de carácter sinfónico con gran capacidad evocadora, en el que la orquesta acompaña el alejamiento de Dante y Virgilio de la oscuridad infernal hacia la luz del día, que avanzan - según la acotación escénica del propio Del Campo en la partitura - "lenta y noblemente con severa majestad clásica [...] denotando la emoción que en sus almas domina"; mientras a lo lejos se escucha la voz de un zagalillo y el repique de las campanas que señalan la llegada del alba. El crítico de La Época destacó el interés de estas partes instrumentales, comentando especialmente esta inserción en el contexto del final de la nueva ópera:

El manejo de la orquesta, es un arte especialísimo de Conrado del Campo, y en la obra actual no sabemos qué admirar más: si su diversidad o su riqueza.

9. Carta de Conrado del Campo a Ángel Barrios desde Madrid con fecha de I3 de diciembre de I9I2 (Granada, Archivo del Patronato de La Alhambra y Generalife, Legado Ángel Barrios). Durante esta década ambos músicos mantuvieron una estrecha relación que se inició como maestro-discípulo, pero que después les llevó a colaborar en varias obras líricas, entre las que destaca la ópera El Avapiés, estrenada en el Teatro Real de Madrid el I8 de marzo de I9I9.

IO. Los folios 166 al final (185) de La tragedia del beso reproducen casi exactamente los compases I5-216 del poema sinfónico La Divina Comedia: Infierno. Ver edición de Editorial de Música Española Contemporánea, 200 I. 
Aquel prólogo, digno de Wagner, contrasta profundamente con el delicioso scherzo con que comienza la acción fundamental; el turbulento y trágico desenlace del drama, con la calma y serenidad que le sucede cuando los poetas inmortales ascienden de las profundidades infernales a la augusta paz de la Naturaleza, envuelta aún en las tinieblas de la noche, poco a poco disipadas. Este fragmento final, que ya hemos oído en conciertos sinfónicos, es de una inspiración elevadísima y de una consecución soberbia ( $\mathrm{La}$ Época, I9-V-I915).

El otro fragmento sinfónico - el prólogo instrumental - no se incorporó a la música de La tragedia del beso, a pesar de que describía la misma situación escénica del comienzo con la llegada de Dante y Virgilio al infierno. No obstante, resulta posible interpretarlo a la manera de obertura, ya que el final del Tranquilo en Sol mayor del prólogo sinfónico enlaza perfectamente con el enérgico arranque del Allegro vivace también en Sol (aunque en modo menor) del comienzo de la ópera. De hecho, algunas críticas parecen sugerir que así se realizó el día del estreno. ${ }^{\text {II }}$

Este carácter sinfónico de la partitura de La tragedia del beso no debe hacernos olvidar la importancia de lo vocal en la ópera, especialmente en las expresivas partes de la pareja protagonista. La soprano que hacía el papel de Francesca, además de su encuentro con los dos poetas en el primer cuadro, debía afrontar un intenso monólogo en el segundo cuadro (ff. IOI-II3). El papel fue estrenado por Ofelia Nieto, quien con sólo quince años iniciaba con esta ópera su prometedora carrera en el Teatro Real; la había descubierto el maestro Vives un ańo antes buscando una protagonista para Maruxa, que encontró en esta destacada alumna de la academia del tenor Simonetti. Rogelio del Villar recordaba años más tarde estas funciones en las que "su voz era algo realmente excepcional, por su calidad, extensión, pureza de timbre y la facilidad y maestría con que la manejaba" (Ritmo, junio 193i). Aunque rara vez afrontó la Nieto el repertorio wagneriano, sus capacidades vocales le permitían afrontar el difícil canto dramático, con su carácter declamatorio y su resistencia vocal en extensión y amplitud. De hecho, algunos críticos censuraron la excesiva dureza de las partes vocales, no sólo la de la soprano, sino también la del tenor, cantado por Pascual Roig, quien se mostró incapaz de afrontar su papel. Eduardo Muñoz en El Imparcial comentó que "Ofelia Nieto luchó con una tesitura despiadada y con una parte fatigosa [...] y el tenor Roig, en quien son de estimar los desesperados esfuerzos que realizó para lograr ser oído, aunque en honor a la verdad no pudo conseguirlo completamente". ${ }^{12}$

II. "De La tragedia del beso conocíamos ya el hermoso prólogo [...]. Al correrse la cortina al terminarse el prólogo, estalló en la sala una formidable salva de aplausos [...]. Se descorrió de nuevo la cortina, y comenzó la acción de la obra propiamente dicha" (Correspondencia de España, I9-V-I9I5).

I2. El Imparcial, 19-V-I915. Con idéntico sentido irónico hacia el tenor se comentaba en el 
El momento culminante de la ópera era el largo dúo de amor de la pareja protagonista (ff. II4-I5I), quienes se encuentran clandestinamente en el jardín antes de ser sorprendidos. Las resonancias tristanescas de la situación escénica se realzaban con un lenguaje cromático de gran intensidad vocal e instrumental de fuerte influencia wagneriana. En la partitura son frecuentes indicaciones como "apasionado", "con vehemencia" o "enérgico", que reflejan la gran fuerza expresiva que busca Conrado del Campo. Además el lenguaje armónico es bastante dinámico e inestable, con un frecuente apoyo en acordes de séptima disminuida y una activa textura orquestal y contrapuntística. Un crítico describió con acierto esta parte como "dúo en el que hay frases apasionadas, que engalana un trabajo orquestal de maestro" (Correspondencia de España, I9-V-1915).
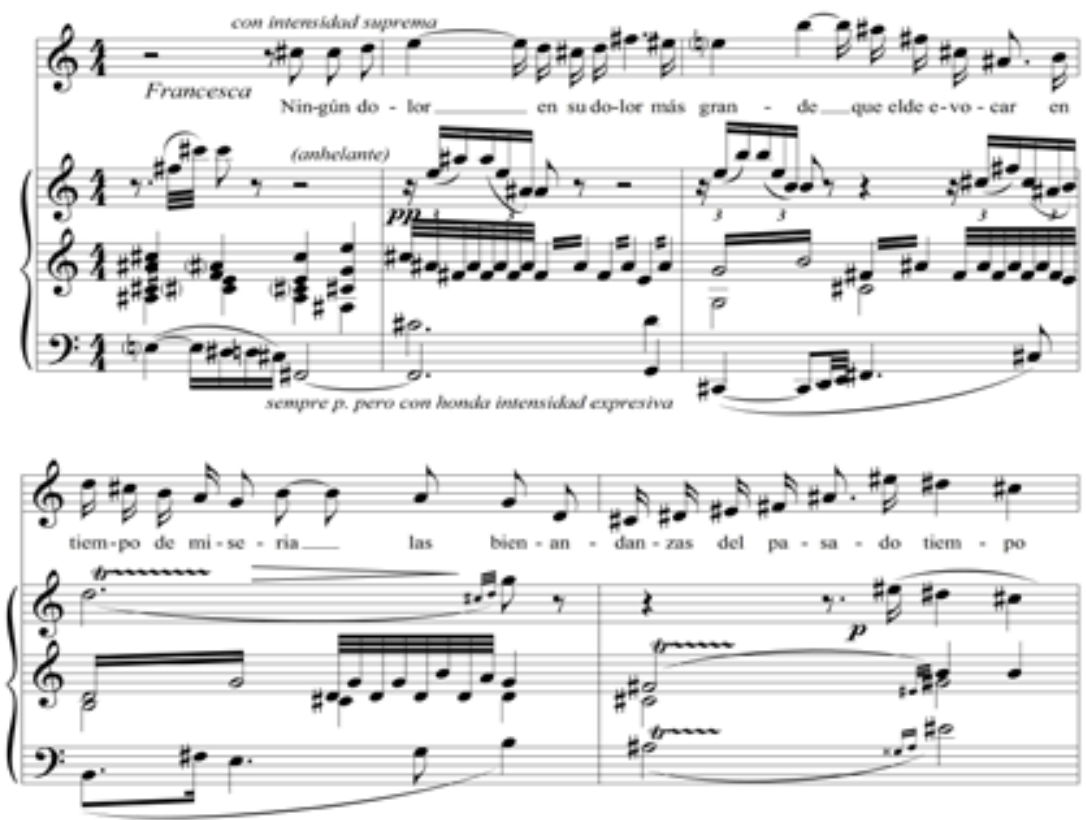

Fig. 8. Conrado del Campo, La tragedia del beso, cuadro I ${ }^{\mathrm{o}}$

No falta en la partitura de Conrado del Campo la musicalización del famoso aforismo con el que contesta Francesca a Dante, lógicamente siguiendo el texto versionado de Carlos Fernández Shaw. Casi un siglo después de la cita en el Otello rossiniano, el contexto musical wagneriano le daba una nueva

diario El Liberal del mismo día: "Del tenor Roig hemos de decir que cuando en algunos momentos le oímos, pudimos percibir qué dice bien." 
dimensión a estas palabras. Las indicaciones en la partitura de "anhelante" y "con honda intensidad expresiva" reflejan así la importancia expresiva del momento.

En definitiva, nos encontramos en La tragedia del beso con una de las obras más wagnerianas no sólo de Conrado del Campo, sino de todo el repertorio operístico español. Las resonancias del Tristán son bastante evidentes, tanto a nivel dramático como musical, fruto de la enorme presencia que tiene este título de Wagner en el ambiente musical madrileño de esta época. El público y la crítica reconocieron esta herencia con división de opiniones. Ya hemos visto cómo Adolfo Salazar y Rogelio Villar defendieron la calidad - e incluso originalidad - del nuevo trabajo operístico. Sin embargo, en el diario $E l$ Liberal se pudo leer: "Pero Tristán e Iseo no se aparta del pensamiento del espectador mientras oye La tragedia del beso. Es una lástima que Conrado del Campo, aún dentro de su manera de ser artista, no haya sabido sustraerse a ese recuerdo" (El Liberal, I9-V-I9I5). Calvo Sotelo, en El Debate, reconociendo su wagnerismo, destacaba la calidad final, que "constituía un jalón capital de este noble empeño" en favor de la ópera nacional:

Patentiza una vez más Conrado del Campo su pericia, más aún, su firmísima sabiduría técnica. La composición es ya para él un arte sin secretos, y aun cuando la armonía se reblandece, deslíe y aún evapora con frecuencia entre el fárrago de notas acumuladas sucesiva y simultáneamente, lo cierto es que jamás falla el maestro, el hombre de ciencia, y que por ello cabe mostrar La tragedia del beso como producción acabada equilibradamente, sin dejadeces ni lapsus que la puedan descomponer. [...] Y luego, Conrado se aferra con exceso al wagnerismo. Es un wagnerista reconcentrado, casi fanático del coloso germano. Fuera de él rechaza todo horizonte. De Wagner es el cromatismo que repetidas veces asoma en la escena de amor. De Wagner es la inflexible línea interna que permanece inquebrantable, pese a la multiformidad extrínseca del adorno musical (El Debate, I9-V-I915).

Lo cierto es que, a pesar del interés de La tragedia del beso y de los aplausos recibidos en su estreno, su repercusión fue bastante escasa. La ópera tardó cuatro años en programarse, siendo estrenada en el Teatro Real de Madrid dentro de la temporada de primavera de i9I5: unas funciones fuera de la temporada principal, dedicadas especialmente a la ópera española, en las que se repuso Margarita la tornera, La Dolores de Bretón y Maruxa de Vives, la obra de mayor éxito estrenada un año atrás en el Teatro de la Zarzuela. Gran parte del público no eran los abonados del resto del año y los precios eran bastante más reducidos. Además, los cantantes eran en su mayoría jóvenes e inexpertos, con la excepcionalidad del precoz caso de Ofelia Nieto. La tragedia del beso fue el único estreno, del que se ofrecieron sólo tres funciones, en un cartel 
que se completó curiosamente con una versión castellana de Bastián y Bastiana de Mozart. ${ }^{\text {I3 }}$

La nueva ópera de Conrado del Campo se estrenaba así por compromiso, debido al prestigio alcanzado por su autor, ya que estaba terminada cuatro ańos antes y se podía haber programado con mayor premura. La dirección corrió a cargo de Arturo Saco del Valle, mientras el propio Conrado del Campo se mantuvo en su atril de las violas, subiendo al final de la representación a recoger los calurosos aplausos. La tragedia del beso se olvidó pronto y su partitura permaneció manuscrita en el archivo de su creador. De esta manera $-\mathrm{y}$ una vez más - el camino de la ópera española no se frenaba por los esfuerzos de los compositores, sino por el total desinterés del ambiente musical hacia la producción nacional. Un poco gratificante camino que no desanimó a un Conrado del Campo, que continuó componiendo óperas hasta el final de su carrera. Y este camino se cruzó con uno de los grandes temas de la historia de la ópera: la representación musical del Infierno de Dante.

\section{BIBLIOGRAFIA}

\section{Estudios}

Cascio, Paolo, 20I4, Estudio y edición crítica de la ópera Francesca da Rimini de Saverio Mercadante (I830), Tesis doctoral, Universidad Complutense de Madrid.

Chiesa, R., 1965, "La Francesca da Rimini di D’Annunzio nella musica di Riccardo Zandonai", Quaderni Dannunziani, 32-33, pp. 320-354.

Colorado, Vicente, 1897, Teatro, 2 vol., Madrid, Ricardo Fé.

Crawford, Francis Marion, 1902, Francesca da Rimini, traducida por Marcel Schwob, París, Eugéne Fasquelle.

Del Campo, Conrado, 2002, La Divina Comedia: Infierno (partitura), MadridBarcelona, Editorial de Música Española Contemporánea.

Dellaborra, Mariateresa, 1997, Antonio Cagnoni e il suo tempo: vita e opere di un compositore all'epoca di Giuseppe Verdi, Milán, Rugginenti.

Fernández Shaw, Carlos, I9IO, La tragedia del beso, poema dramático en tres cantos, Madrid, Sociedad de Autores.

—, 1947, El canto que pasa: antología poética (I883-I9II), Madrid, M. Aguilar.

一, 1966, Poesías completas, Madrid, Gredos.

Fernández-Shaw, Guillermo, 1969, Un poeta de transición. Vida y obra de Carlos Fernández Shaw, Madrid, Gredos.

Gómez, Julio, 1956, Los problemas de la ópera española, discurso de ingreso leído el 17 de junio de 1956, Madrid, Real Academia de Bellas Artes de San Fernando.

13. El crítico del diario $A B C$ (I9-V-I9I5) definió acertadamente la visión de los asistentes del Teatro Real a esta ópera de Mozart: "El público sabía que iba a admirar una monada, un bijou, una miniatura, a la que la antigüedad presta más valor, por lo mismo que al través de ella ha conservado su lozanía y la gracia de su concepción, y acudió solícito y oyó con verdadera devoción Sebastián y Sebastiana, esa deliciosa plática de familia en la que tres únicos personajes se lo cantan y se lo recitan todo." 
Huebner, Steven, 1999, French Opera at the Fin de Siècle, Oxford University Press. Iberni, Luis G., I995, Ruperto Chapi, Madrid, ICCMU.

Lozano, Pilar, I962, "Archivo epistolar de Carlos Fernández Shaw", Revista de Literatura, XXII, no 43-44 (julio-diciembre), Madrid, Instituto Miguel de Cervantes de Filología Hispánica, pp. I25-210.

Mancinelli, Luigi (música); Arturo Colautti (versi), 1907, Paolo e Francesca. Drama lirico in un atto, Milán, Sonzogno.

Mariani, Antonio, 1998, Luigi Mancinelli. La vita, Lucca, Akademos.

Norris, Geoffrey, 1993, Rachmaninoff, Londres, Dent \& Sons.

Sánchez Sánchez, Víctor, 20ıо, "Resonancias tristanescas en la ópera española. Wagnerismo en las óperas de Conrado del Campo", Anuario musical, 65, pp. I45-I7O.

—, 20Iob, "El 'Germanismo Violento' en la obra de Conrado del Campo”, en Cruces de caminos: intercambios musicales y artísticos en la Europa de la primera mitad del siglo XX, Gemma Pérez Zalduondo y María Isabel Cabrera García (coord.), Universidad de Granada, pp. 217-262.

Villanueva, Carlos, 20II, "La flor del agua, zarzuela de Conrado del Campo y Víctor Said Armesto: notas oportunas al hilo de un centenario", Revista de Musicología, 34/I, pp. I67-20I.

-, 20I4, Victor Said Armesto. Una vida de romance, Santiago de Compostela Consorcio de Santiago.

\section{Prensa}

La Época, 27-IV-I908: C. Roda: “De Música: Orquesta Sinfónica”.

El Mundo, I4-III-ı9ıo: B. G. de C., "Beneficio de María Guerrero: La tragedia del beso".

Diario Universal, I5-III-ı9ıo: Alejandro Miquis [Anastasio Anselmo González y Fernández]: "En La Princesa: beneficio de María Guerrero".

España Nueva, I5-III-I9ıо: V., "Tardes de estreno: beneficio de María Guerrero".

El Mundo, I5-III-I910: "Beneficio de María Guerrero".

El Universo, I5-III-I9ıо: C. de A.: "Crónica teatral”.

Revista Musical, Bilbao, año III, no 4 (abril I9II): Miguel Salvador: "Madrid: Teatro Real”.

Diario de Cádiz, 26-IV-I9ıо: "La tragedia del beso".

El Pais, I7-IV-ı9ıо: "Teatro Real: Orquesta Sinfónica”.

El Mundo, I8-IV-r9ıо: Manuel Manrique de Lara: "Orquesta Sinfónica”.

El País, I9-IV-r9io: L. A.: "Orquesta Sinfónica”.

Revista Musical, Bilbao, año IV, n.I (enero I9I2): "Noticias".

El Imparcial, 30-X-1913: Ricardo Blasco: "La Sinfónica en París".

La Época, 3-II-I9I5: A. Barrado: "Teatro Real: Estreno de Paolo e Francesca”.

Revista Musical Hispano-Americana, II Época (año VII), n.I3 (febrero I9I5): E.

Echeveouren: "Extranjero: Roma, enero I915".

El Pais, I9-V-r9i5: R. V. [Rogelio Villar]: "La tragedia del beso",.

La Época, Madrid, I9-V-I9I5: Interino: "Real: La tragedia del beso".

Correspondencia de España, I9-V-I915: N. R. de C.: "Teatro Real".

El Imparcial, I9-V-ı915: Eduardo Muñoz: "La tragedia del beso".

El Liberal, 19-V-ı915: Tristán: "Teatro Real".

El Debate, I9-V-i915: Calvo Sotelo: "Los estrenos de anoche".

$A B C$, I9-V-I9I5. 
Arte Musical, 2I-V-I9I5: Adolfo Salazar: "La tragedia del Beso". Arte musical, junio I915: Adolfo Salazar: "La Tragedia del Beso".

La Época, IO-XII-I926: Víctor Espinós: "La ópera en la Zarzuela: estreno de Francesca da Rimini”.

Ritmo, no 33, junio 1931: [Rogelio Villar]: "Ofelia Nieto”.

\section{Listado de figuras}

Fig. I. Rossini, Otello, acto III (canto del gondolero). Ed. Breitkopf \& Härtel, Leipzig, I8I6, pp. I55-I56.

Fig. 2. Rachmaninof, Francesca da Rimini. Moscú, Gutheil, I906, p. 54.

Fig. 3. Conrado del Campo, La Divina Comedia: El Infierno, Final. Partitura del Legado Conrado del Campo, Centro y Documentación Archivo de la SGAE (CEDOA-SGAE).

Fig. 4. Carlos Fernández Shaw, Nota manuscrita con el listado de fuentes. Biblioteca Fundación Juan March, CFS-68A.

Fig. 5. Conrado del Campo, copia revisada del libreto de La tragedia del beso, pp. I6I7. Legado Conrado del Campo, Centro y Documentación Archivo de la SGAE (CEDOA-SGAE).

Fig. 6. Conrado del Campo, La tragedia del beso, inicio del cuadro $2^{\circ}$. SGAE, Fondo "Teatro Lírico" MPO/3IO, fols. 58v-59r.

Fig. 7. Conrado del Campo, La tragedia del beso, cuadro Io. SGAE, Fondo "Teatro Lírico" MPO/3Io, fols. 22r-23r.

Fig. 8. Conrado del Campo, La tragedia del beso, cuadro I ${ }^{\circ}$. SGAE, Fondo "Teatro Lírico" MPO/3io, fol. 44v. 